BLS 35, No 1 2009. DOI: http://dx.doi.org/10.3765/bls.v35i1.3612

(published by the Berkeley Linguistics Society and the Linguistic Society of America)

\title{
A Tautology is a Tautology: Specificity and Categorization in Nominal Tautological Constructions
}

\author{
IKSOO KWON \\ University of California, Berkeley
}

\section{Observation}

Okamoto (1993) sheds light on the construal of Japanese nominal tautological constructions with regard to its language specificity. She argues that meanings of tautologies in Japanese are determined by the case markers -wa (topic marker), and - $g a$ (subject marker), which leads to construals of immutability of category and undesirability, respectively. It seems to be implied that the meaning distribution is complementary except for some cases (see Okamoto 1993). One of the examples can be shown as below:

(1) kimi wa kimi, ware wa ware nari, saredo nakayosi.

you Top you I Top I Cop yet, (we) are good friends

'You are you, I am I, yet we are good friends.'

(from the newspaper Asahi Shinbun) [Okamoto 1993:443]

As shown in (1), if the topic marker $-w a$ is used in the construction, the author argues that it conveys immutability of the category for the referred nominal in question, but not undesirability of the nominal. However, there are some cases where desirable meaning can be derived even though the topic marker -wa is used:

(2) [When seeing a student, who has been known for his brilliance, solving a very tough question in a second without any hesitation,]

$$
\begin{aligned}
& \text { tensai wa tensai-da } \\
& \text { genius Top genius-Decl } \\
& \text { lit. 'Genius is a genius' (HE IS a genius). }
\end{aligned}
$$

If it is true that the construction with the topic marker can convey either (un)desirable or category immutability reading, Okamoto's argument that mean- 


\section{Iksoo Kwon}

ings are determined only by grammatical markers would not be convincing enough (further to be discussed below).

Similar to the Japanese constructions, construal of Korean tautologies seems to be determined by case markers such as -un/-nun (topic marker), and $-i /-k a$ (subject marker). However, their semantic ranges also overlap with each other so that the construal of one sentence such as (3) varies:

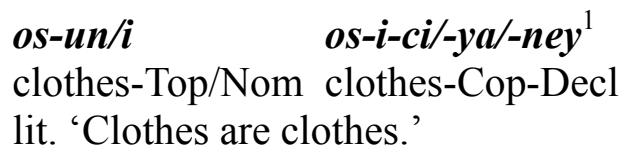

It can be equivalent to saying, 'This outfit can be barely called as an outfit,' 'That IS an outfit,' or 'That's nothing but an outfit,' depending on various contexts. If the meaning distribution only relied on grammatical markers, the semantic overlap shown above would not be expected.

The aim of this paper is to argue that the interpretation depends on the speaker's knowledge about the entity with regard to its specific/generic distinction and on the speaker's categorization of the referred entity, rather than only on language specific conventionality. Furthermore, this paper will relate the construal of tautologies to cognitive categorization processes regarding shared knowledge, expectation, and inferences. This paper will account for the meaning distribution of tautologies in general by considering some relevant examples from Korean and Japanese within the framework of Mental Spaces Theory (Fauconnier and Turner 2002; MST, henceforth), which provides an outstanding theoretical window through which we can account for interrelation of the two nominals in the construction.

In section 2, the paper explores background on this topic-recapitulation of the 1980's debate and advent of non-radical approaches and revisits one of the non-radical approaches, Okamoto's (1993) accounts. Then, the paper raises some problems in her accounts. In section 3, by analyzing Korean tautological examples, it is argued that construal of tautological constructions should be based on two cues-specificity and categorization. In section 4, based on the analyses, detailed explication of the construction will be provided within Mental Spaces Theory. Finally, a residual issue-similar semantic effects of tautologies to proverbs - will be discussed briefly in section 5 .

\section{A Concise Overview of the Debate Over Tautologies}

In general, tautologies are regarded as redundant expressions and true by virtue of their logical form alone, from the perspective of truth-conditional semantics (Okamoto 1993:434). However, frequent use of colloquial tautologies has been studied by more than a few linguists, and the topic has given rise to overheated

\footnotetext{
${ }^{1}$ One of the endings -ney is not to be used as freely as the other two endings. In fact, the ending is one of evidential markers in Korean and I will argue that this evidential marker makes us a crucial evidence for relevance between the subject noun and specificity (to be discussed in section 3 ).
} 


\section{Nominal Tautological Constructions}

debate between radical semanticists (Wierzbicka 1987 and 1988; inter alia) and pragmaticists (Brown and Levinson 1987, Levinson 1983, Ward and Hirschberg 1991) in the late 1980's (Radical Approaches). The pragmaticists argue that meanings of tautologies are regarded as conversational implicatures which are calculable from general, language-independent conversational principles, such as the Gricean Cooperative Principle combined with the flouting of the maxims of Quantity (Brown and Levinson 1987), whereas the semanticists argue that the communicative import is conventionally encoded in a given construction, and is not calculable from any language-independent pragmatic maxims (Wierzbicka 1987). This debate itself shows that it would not be simple to say that tautologies are semantically vacuous, and there must be some kind of mental process in construing tautologies.

Meanwhile, it is noteworthy that non-radical approaches toward the topic have been conducted by many linguists (Escandell-Vidal 1990, Farghal 1992, Gibbs and McCarrell 1990, Gibbs 1994, Okamoto 1993), who thought that construing tautologies is possible only when we take into account speakers' embodied knowledge of the entity which is talked about as well as linguistic forms. They thought that linguistic forms trigger language-specificity in construing tautologies to some extent, but that it is also true that people's inferencing plays a crucial role to have additional pragmatic meaning extensions.

This paper agrees with the non-radical approach, since the speaker's embodied experience of the referred nominal as well as grammatical conventionality is found to be crucial to the construal.

\subsection{Problem Raised}

Among non-radical approaches, Okamoto's (1993) accounts are intriguing in that she argues that the core meanings are fixed by conventionality before pragmatic inferences are used. There are major core meanings for the tautologies and they are determined by grammatical markers such as a topic marker - wa and a subject marker - $g a$. These markers yield specific readings such as category immutability and undesirability respectively.

The construal is, however, not totally fixed by conventionality as shown in (2) containing the topic marker -wa. In addition, when $X$ ga $X$ is employed, it indicates that the referent of $X$ has some undesirable quality (Okamoto 1993:448). This account is, however, not impeccable, since there is a case where the very same construction can convey the desirable attitude toward the nominal X.

(4) [The speaker is talking about the very formal wedding to which she is invited.]

basyoga basyo da kara, tyanto site ik-anakutya place Sub place Cop because, in a proper (dress) (I) must go 'Because the place is (not an ordinary) place, I must go in a proper dress.' [Okamoto 1993:450] 


\section{Iksoo Kwon}

As shown above, the example does not necessarily presuppose that the place is undesirable. Rather, the place is likely to be merely a formal place.

In short, core meaning distribution only by grammatical markers does not seem to be convincing, since each construction can convey either the (un)desirability reading or the category immutability reading. In this regard, Okamoto's criteria of semantic distinctions needs to be reconsidered and strengthened with another criterion.

\subsection{Implications of the Counterexamples Against Okamoto (1993)}

Considering the counterexamples presented above, core meaning seems to be determined by other semantic cues: The construal seems to depend on whether or not the entity which is talked about evokes a specific entity in the interlocutor's mind. That is, if she refers to a specific entity, the reading is likely to be either reading of undesirable or desirable attitude toward the nominal; If not, the category immutability reading can be evoked. ${ }^{2}$ In order to have a meaning of (un)desirability, it would be natural that people have the relevant experience of the entity, which is related to the specificity of the noun phrase. For instance, if we do not have any specific person in mind, we cannot say tensai wa tensai da 'the genius is a genius' as a compliment or an insult. Instead, it would mean something like 'there is nothing special about a genius.' The working hypothesis can be recapitulated as follows:

a. If a nominal $\mathrm{X}$ refers to a specific entity, the utterance is likely to convey a reading of desirability or undesirability.

b. If a nominal $X$ refers to a general notion of the concept, the utterance is likely to convey the reading of category immutability.

$b^{\prime}$. If both nominals refer to the same type of entity (specific-specific or generic-generic; "token indifference" (Gibbs and McCarrell 1990)), it is likely to convey category immutability.

This suggestion is far from being new: Farghal (1992) argues that various interpretations can be derived from the specific/generic distinction via our inferences based on expectation. He argues that absolute generalizations, fatalism, obligation, and indifference fall into the category where a generic notion is referred to, whereas assessment falls into the other category where a specific entity is referred to. In addition, Gibbs (1994) argues that the construal of the construction is based on a stereotypical understandings of the nominal.

\footnotetext{
2 As Elizabeth Traugott points out, 'category immutability' reading might accompany construal of negative nuance in general, which means that purely semantic interpretation of the construction will readily call for some pragmatic inferences. Nevertheless, the author would like to assume for now that we can have that reading equivalent to 'token indifference' reading, which is assessmentneutral. As a matter of fact, this point is directly related to this paper's main claim: construal of the construction is determined by interaction of the interlocutor's sophisticated specificity distinction and categorization and thus, it is often times not easy to label the readings.
} 


\section{Specificity in Cross-Linguistic Tautological Constructions: Korean}

This section explores the possibility that specificity lies in the center of construal of the construction cross-linguistically, by investigating Korean nominal tautologies. If the hypotheses are right, it would not be impossible to say that what matters most in the construal is how specificity is fused into the utterance.

\subsection{Multiple Readings from a Single Utterance}

Korean has a similar case marking system to Japanese: A topic marker -un/-nun and a subject marker $-i /-k a$ and thus, the construction might be analyzed in a similar fashion: The topic marker -un/-nun evokes category immutability reading, and the subject marker $-i /-k a$ evokes undesirability reading. However, as shown in (3), it is not hard to find that a single expression can be interpreted in multiple ways. Let us take another example, which is shown in (6)-(8):

(6) [Someone asks the speaker if $X$ is the speaker's friend and the speaker is not sure about that]

$\begin{array}{llll}\text { na-eykey } & k u-u y & \text { cenhwapenho-ka } & \text { iss-nun-kes-ul } \\ \text { I-to } & \text { he-Gen phone.number-Nom Cop-Pres-Nmlz-Acc } \\ \text { po-ni } & \text { chinkwu-nun } & \text { chinkwu-ney } \\ \text { see-because } & \text { friend-Top friend-Decl }\end{array}$

lit. 'Because I have his number, the friend is a friend'

(Considering that I have his number (in my cell phone), he might be my friend (I might have met him before)

$\begin{array}{lll}\text { tow- } a & \text { cwu-ese } & \text { cengmal koma-we } \\ \text { help-Conn } & \text { give-Conn.because really thank (you)-Decl } \\ \text { yeksi } & \text { chinkwu-nun } & \text { chinkwu-ney } \\ \text { doubtlessly } & \text { friend-Top friend-Decl }\end{array}$

lit. 'Thank you for giving me help. The friend is a friend, doubtlessly' (Thank you for giving me help. YOU'RE a friend.)

(8) [When advising your friend, who is afraid that friendship will turn to be bad and hesitates to tell her friend to give her money back, not to hesitate to,]

$\begin{array}{ll}\text { ese tal-lako } & \text { ha-e. } \\ \text { soon give.me-Comp do (say)-Decl }\end{array}$

$\begin{array}{llll}\text { ton-un } & \text { ton-i-ko, } & \text { chinkwu-nun } & \text { chinkwu-ya } \\ \text { money-Top money-Cop-and } & \text { friend-Top } & \text { friend-Decl }\end{array}$

lit. 'Tell him to give you the money back as soon as possible. Money is money and Friends are friends' (Tell him to give you the money back quickly. The thing is that money and friendship are separate matters.)

In (6)-(8), the same utterance is used with different meanings: The one used in example (6) conveys the meaning that even though I don't know him very well, I will call him a friend, since I have him in my phonebook (evaluative), especially 


\title{
Iksoo Kwon
}

somewhat negative attitude. Next, in (7), the speaker would like to express gratitude toward the hearer, who is the speaker's friend by meaning that the hearer is a real friend. The construction conveys another evaluative reading, especially positive attitude toward the nominal. Last, in (8), the construction does not convey any evaluative reading. Rather, it focuses on the immutability of the category FRIEND, regardless of the money matter.

It is worth noting that we can obtain other kinds of reading such as indifference and fatalism (Farghal 1992; in Jordanian Arabic), when the speaker does not have a specific entity in her mind, which can be exemplified in Korean as follows:

\author{
A: chinkwu-ka mwue-lako sayngkak-ha-ni? \\ friend-Nom what-Comp thought-do-Intr \\ B: chinkwu-nun chinkwu-ci. \\ friend-Top friend-Decl \\ lit.'What do you think is a friend? Friends are friends' \\ (How do you define a friend? There is nothing special about a friend)
}

In (9), the construction conveys meaning of indifference. That is, the speaker B implies that he does not want to think about the matter seriously. In this case, if the speaker has a specific person who is referred to by the nominal, we cannot get the reading.

\subsection{Evidence Showing Specificity \\ 3.2.1. Evidentiality}

One compelling source of evidence comes from the evidential marking system in Korean. According to H.-S. Lee (1991), Korean ending markers can express various types of aspects, epistemicity and evidentiality. As already used in our examples above, the ending markers such as $-c i /-y a /-n e y$ play the role of aspectual marker. The first two markers are related to describing the speaker's belief of the proposition in question: Specifically, the marker $-c i$ is called a committal marker by H.-S. Lee (1991). The last marker, -ney, functions as an evidential marker (H.S. Lee 1991), since the marker cannot be used unless the speaker has a visual access to an entity or a person that is talked about.

If this is the case, the nominal tautologies that are construed as category immutability will not be compatible with the evidential marker -ney, because the reading requires that the referred entity be non-referential, whereas the evidential marker presupposes that the referred entity is referential. This prediction turns out to be correct: The utterance os-un os-i-ney [clothes-Top clothes-Cop-Evid] 'clothes are clothes' cannot have the category immutability reading, since it contains the evidential marker. Other evidential markers such as -tela [retrospective evidential], -kes kathta 'it seems-...' are also not compatible with the reading in general. 


\section{Nominal Tautological Constructions}

\subsubsection{Negation}

The argument that specificity matters in the construal can be supported by negating a tautological construction with a category immutability construal. For instance, if the sentence is negated as (10) below, the sentence cannot make sense without any specific entity referred to in the speaker's mind:

$$
\begin{aligned}
& \text { *os-un/ } i \quad \text { os- } i \quad \text { ani-ya } \\
& \text { clothes-Top/ Sub clothes-Sub Neg.Cop-Decl } \\
& \text { '(Lit.) clothes are not clothes' }
\end{aligned}
$$

(10) does not make sense for an obvious reason: If there is no entity to deny, we simply cannot deny it. So to speak, if we could deny the category itself, i.e. clothes, it would be impossible to logically say that the category member does not belong to the category. Thus, if (10) makes sense, the only way is that the nominal should refer to a specific entity. Along this vein, with a generic reading of the nominal, we can obtain the category immutability reading, rather than the (un)desirability readings.

\subsubsection{Grammatical Referentiality}

Languages have grammatical or lexical devices which denote specificity: For instance, in Korean, the definite articles $k u$ and proper nouns. If specificity matters in the construal of the construction, these two devices would affect the construal of the construction when they are used in it. This sub-section will explore their usages in the construction.

To begin with, let us explore the usage of the definite article in the construction. With our familiar example 'clothes are clothes,' can we explore the definite article usage.

(11) [A couple goes shopping. While shopping, the husband gets bored and tired of looking around, but his wife keeps looking at clothes. By and by, his wife picks an outfit and asks him what he thinks about it. The husband can mean 'I don't care about it, just pick anything and let's go home,' by saying the following utterance.]
ku-os-un/-i
ku-os-i-ci/-ya/-ney
the-clothes-Top/Sub the-clothes-be-Decl1/-Dec12/-Dec13
'The clothes are the clothes.'

This utterance does not carry an evaluative meaning: It conveys an indifference reading via the category immutability construal. The interesting thing is that despite that this utterance employs the demonstrative $k u$, the utterance can be used without the speaker's pointing out any specific outfit. This example might show that as discussed above in $\left(5 b^{\prime}\right)$, if the same type of nominals are used within a single tautology, the speaker would take the expressions only at the surface- thus 


\section{Iksoo Kwon}

yielding the category immutability reading (Token Indifference). Consequently, we can learn that only with specificity of the first nominal, we cannot grasp the construal perfectly.

\subsection{Evidence Showing Prototypicality of the Predicative Nominal}

The fact that what the second nominal refers to affects the semantics of the constructions is supported by Gibbs and McCarrell's (1990) experiments. They argue that how speakers/listeners understand stereotypes of people, activities, and concrete objects in the use of tautologies definitely affects how they understand different tautological expressions. For example, comparing utterances such as $A$ hat is a hat vs. Business is business, the latter is more readily understood. This suggests that in the construal of tautologies, people's categorization with regard to their cognitive reference point must be involved and this paper argues that the categorization process occurs when we process the predicative nominal. The relevance of this second cue can be found in the usage of proper nouns.

Proper nouns in general, are an unmarked grammatical category that is referential. In a similar vein, we can expect that the same tendency can be accounted for in the usage of proper nouns in the construction. See the following example:

pwusi-nun pwusi-ney

Bush-Top Bush-Decl

lit.'Bush is Bush' (HE IS great!/ HE IS stupid!/ I don't care about him)

Since 'Bush' denotes a specific person, the construction is likely to convey an evaluative reading. However, if someone who does not know who Bush is heard this utterance, it could not convey any meaning to him/her. Rather, it makes sense only when the speaker has a personal attitude toward the person. In this vein, this example shows that the construal of the construction deals not only with specificity, but we need, in addition, to link the topic to what we believe about the nominal, which could be a prototype, stereotype, peripheral member of the category, and so forth.

In sum, this section argued that the construal of the Korean nominal tautologies seems to be determined by the specific/ generic information of the nominal. ${ }^{3}$ However, this criterion alone is unable to account for all the phenomena. It seems that we need another parameter, which is what we believe or expect about the nominal, which thus could be a prototype, a stereotype, a member of the category,

${ }^{3}$ It is brought to my attention that double subject construction in Korean is possible only when the first nominal is specific:

(a)

$$
\begin{aligned}
& \text { os-i } i \text { os-un os-i-ney } \\
& \text { clothes-Nom clothes-Top clothes-Cop-Decl } \\
& \text { 'This clothes is great.' / 'This clothes is horrible.' }
\end{aligned}
$$

(a) is not licensed when the nominal refers to a generic category. In this respect, specificity distinction plays a critical cue for the construal. 


\section{Nominal Tautological Constructions}

the category itself, etc. Based on these observations, this paper will argue eventually that the meaning distinction in terms of evaluative reading and category immutability reading is meaningless, as a matter of fact. Rather, it will argue that specificity and the speaker's categorization of the nominal are the critical cues for a construal and will account for patterns of the construal of the tautologies within Mental Spaces Theory with regard to specificity, information structure, and categorization.

\section{Construal of Nominal Tautologies Within Mental Space Theory}

The construal of Korean nominal tautologies seems to be due to the interactive mappings between an entity in the real world (around the interlocutor), an introduced entity in the topic, and the speaker's belief about the entity. In short, we construe the construction with the first nominal's specificity and the second nominal's categorization process. In this section, the paper shows how linguistic cues and our inferences interact each other by means of Mental Spaces Theory (Fauconnier and Turner 2002).

\section{1. $\quad$ Specificity and Categorization}

When we refer to a specific entity, it is presumed that the speaker knows what it is and the hearer does not have to know what it is. It can be represented in a mental space where the referred entity is linked and grounded to the other entity in base space. Let us exemplify the previous example 'Friends are friends' or 'A friend is a friend,' which is attested to be able to be used in various contexts and is repeated in (13):

chinkwu-nun chinkwu-ney

friend-Top friend-Decl (lit. 'friend is friend')

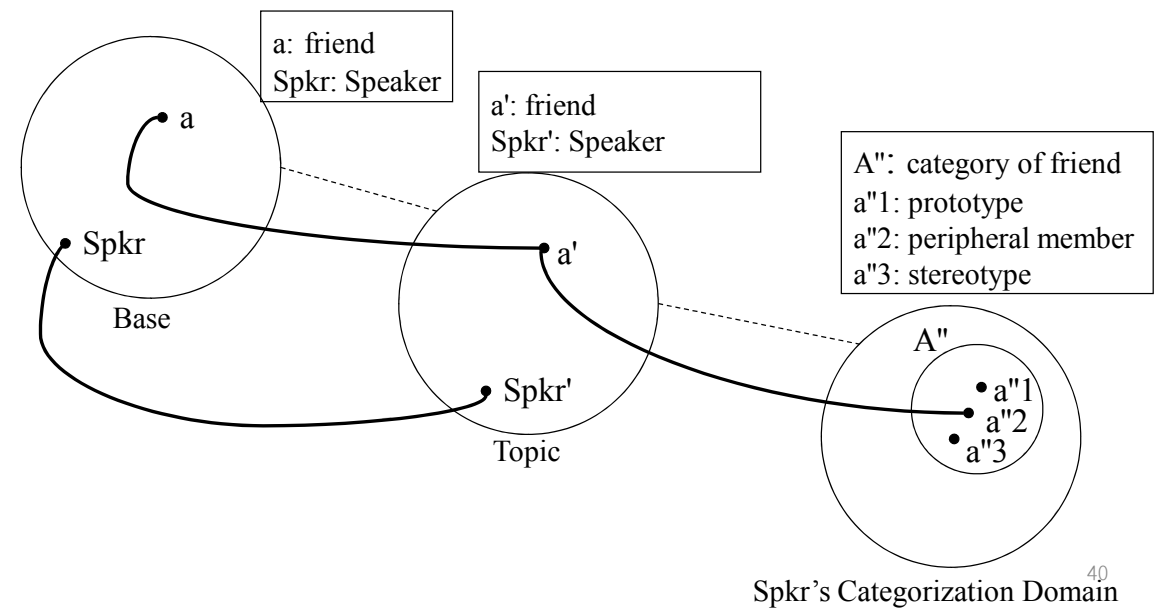

Let us assume that (13) is used as conveying desirable and undesirable readings. These readings require that the speaker should have a specific entity in her mind. The specific entity in the speaker's mind is represented as $a$ in the base space in (14). Since the entity is introduced as a topic in the utterance thanks to the topic 


\section{Iksoo Kwon}

marker, the topic space is established, where the entity as a topic exists ( $\left.a^{\prime}\right)$. The entity could be anything that can be called a friend as shown in the Topic space above. The two roles $a$ and $a^{\prime}$ are linked to each other, since the speaker has to have specific knowledge about the entity, which means the speaker has to have access to the entity in the base. Now, based on the information about the real entity in the speaker's mind, she can evaluate the entity and encode her attitude toward it into the utterance.

Notice that to evaluate something presupposes that there should be another hypothetical entity with which she can match it, and this hypothetical entity is represented in an Expansion space. This notion is equivalent to Rosch's (1975) cognitive reference points in that when uttering the sentence, people are likely to have a special reference point in reasoning, especially in making approximations and estimating size etc (Lakoff 1987:88). Thus, the construal could vary depending on which element in the Expansion space the entity in the topic space $a^{\prime}$ is linked to. That is, the category in the Expansion space can be specified into a prototype (ideal and typical; $\left.a^{\prime \prime} 1\right)$, a peripheral member $\left(a^{\prime \prime} 2\right)$, and a stereotype ( $\left.a^{\prime \prime} 3\right)$.

\subsection{Genericity and Categorization}

As discussed above, if the speaker does not denote any specific entity in her mind, the construction would convey the so-called category immutability reading. In this case, the entity in the Topic space does not have to be linked to the one in the Base space. As for the same example discussed in section 4.1, we can account for the immutability reading with a different diagram, which is shown in (15).

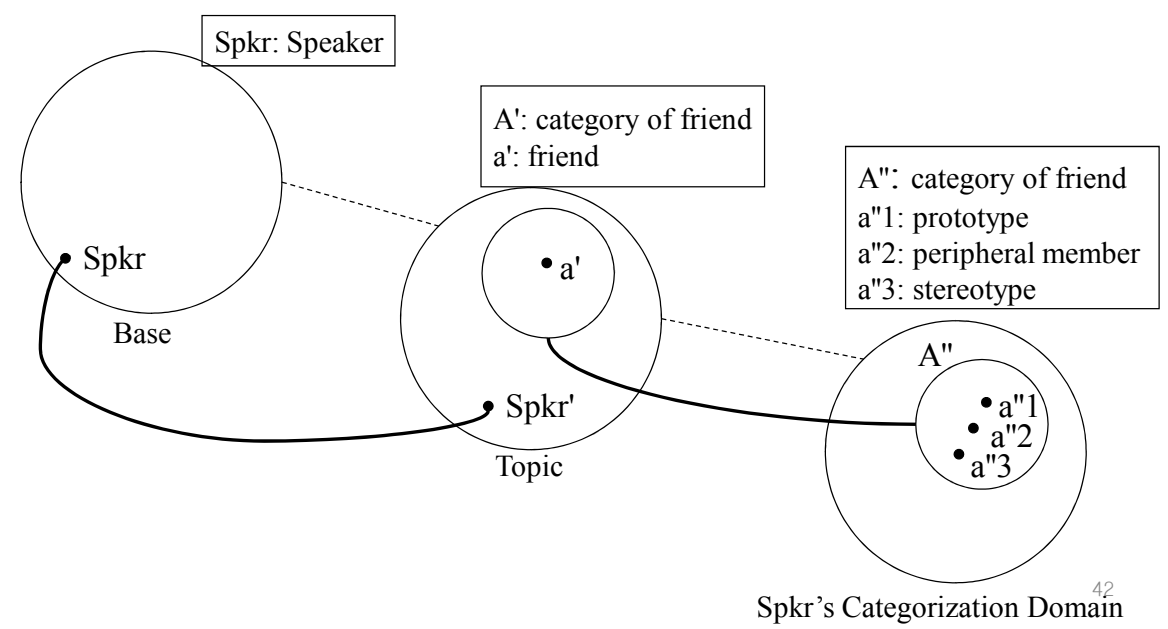

As shown in (15), there is no such entity FRIEND that the speaker can have access to in the Base space. In the Topic space, the category of $A^{\prime}$ instead of individual member a', is linked to the category of $A^{\prime \prime}$ in the speaker's categorization space. This linking yields the meaning of category immutability. This might be related 


\section{Nominal Tautological Constructions}

with Lakoff's (1987:87) observation that many categories are understood in terms of abstract ideal cases - which may be neither typical nor stereotypical.

\section{General Discussion}

If the construal of nominal tautologies is determined by the interaction between the two nominals, we might not need categories of the construals such as category immutability, evaluative, etc. That is because, first, it is not easy to label the construals due to their subtle meaning differences and second, the semantic mappings between them will take care of the construal process.

What is interesting about some nominal tautologies seems to be that they have similar illocutionary force as proverbs. When hearing an utterance, e.g. boys will be boys, interlocutors can infer that the generic expression in the utterance will apply to the specific target in the given context, e.g. a couple is talking about their son, while watching their son messing around in the room. In this context, even though the utterance does not contain any specific expression, the interlocutors infer that the generic expression boys will, somehow, apply to the specific child, their son, in the given context. The interpretation of the tautology involves some similar kind of specification/abstraction process to GENERIC IS SPECIFIC mapping, which is crucial for our understanding of proverbs. This similarity in the cognitive processes causes interlocutors to think that tautologies have the similar semantic effects as proverbs.

Another intriguing issue is the relationship between information structure and evidential ending. We have discussed that the evidential ending -ney cannot go with the category immutability reading. The interesting thing is that when the evidential marker is in use, the subject marker $-i /-k a$ is not licensed in general. This suggests that the evidential marker is sensitive to information structure: If an entity is marked as old information and topicalized, it is more readily regarded as a specific entity based on the interlocutors' shared knowledge, and thus, the topic marker goes well with the evidential marker.

\section{Concluding Remarks}

This paper argued that in order to construe nominal tautologies, it is crucial to understand how specificity affects the construal and showed the interaction between two nominals in the construction within the framework of Mental Spaces Theory. It is also argued that the construal is affected by what the second nominal expression denotes: The second nominal expression evokes a whole category where a prototype, a peripheral member, a stereotype, the category itself, etc. and that what the second nominal expression denotes determine the meaning.

In closing, I confess that the other factors, such as tonal contour and ending markers that might affect the construal of Korean nominal constructions are not fully discussed. There might be some other semantic cue for the construal distribution: Tonal contour and various ending markers in Korean. Tonal contour seems to make contrast clearly depending on which meaning the construction conveys and ending markers are so subtly different in their semantics. These call for future research. 
Iksoo Kwon

\section{References}

Brown, Penelope and Stephen Levinson. 1987. Politeness: Some universals in language usage. Cambridge: Cambridge University Press.

Escandell-Vidal, Victoria. 1990. Nominal tautologies in Spanish. Paper presented at the 1990 International Conference on Pragmatics, Barcelona, Spain.

Farghal, Mohammed. 1992. Colloquial Jordanian Arabic tautologies. Journal of Pragmatics 17:223-240.

Fauconnier, Gilles, and Mark Turner. 2002. The way we think: Conceptual blending and the mind's hidden complexities. New York: Basic Books.

Fraser, Bruce. 1988. Motor oil is motor oil: An account of English nominal tautologies. Journal of Pragmatics 12:215-220.

Gibbs, Raymond W. 1994. Colloquial tautologies. The poetics of mind: Figurative thought, language, and understanding, 345-351. Cambridge: Cambridge UP.

Gibbs, Raymond W., and Nancy S. McCarrell. 1990. Why boys will be boys and girls will be girls: Understanding colloquial tautologies. Journal of Psycholinguistic Research 19-2, 125-145.

Grice, H. Paul. 1975. Logic and conversation. In J.L. Morgan and P. Cole, eds., Syntax and semantics, Vol. 3, Speech acts, 41-58. New York: Academic Press.

Lakoff, George. 1987. Women, fire and dangerous things: What categories reveal about the mind. Chicago and London: Chicago University Press.

Lee, Hyo-Sang. 1991. Tense, aspect, and modality: A discourse-pragmatic analysis of verbal affixes in Korean from a typological perspective. Ph.D. diss., University of California, Los Angeles.

Levinson, Stephen C. 1983. Pragmatics. Cambridge: Cambridge University Press.

Okamoto, Shigeko. 1993. Nominal repetitive constructions in Japanese: The tautology controversy revisited. Journal of Pragmatics 20:433-466.

Rosch, Eleanor. 1975. Cognitive reference points. Cognitive Psychology 7:532-547.

Ward, Gregory L., and Julia Hirschberg. 1991. A pragmatic analysis of tautological utterances. Journal of Pragmatics 15:507-20.

Wierzbicka, Anna. 1987. Boys will be boys: 'Radical semantics' vs. 'radical pragmatics.' Language 63:95-114.

Wierzbicka, Anna. 1988. Boys will be boys: A rejoinder to Bruce Fraser. Journal of Pragmatics 12:221-224.

Iksoo Kwon

University of California, Berkeley

Department of Linguistics

1203 Dwinelle Hall

Berkeley, CA 94720-2650

kwoniks@berkeley.edu 